\title{
Hypertriglyceridemia-induced acute pancreatitis: A prospective, multicenter, international cohort analysis of 716 acute pancreatitis
}

\section{cases}

Dóra Mosztbacher a, b, c, Lilla Hanák ${ }^{\mathrm{b}}$, Nelli Farkas ${ }^{\mathrm{d}}$, Andrea Szentesi ${ }^{\mathrm{b}, \mathrm{e}}$, Alexandra Mikó ${ }^{\mathrm{f}}$, Judit Bajor ${ }^{\mathrm{f}}$, Patrícia Sarlós ${ }^{\mathrm{f}}$, József Czimmer ${ }^{\mathrm{f}}$, Áron Vincze ${ }^{\mathrm{f}}$, Péter Jenő Hegyi ${ }^{\mathrm{b}}$, Bálint Erőss ${ }^{\mathrm{b}}$, Tamás Takács ${ }^{\mathrm{g}}$, László Czakó ${ }^{\mathrm{g}}$, Balázs Csaba Németh ${ }^{\mathrm{g}}$, Ferenc Izbéki ${ }^{\mathrm{h}}$, Adrienn Halász ${ }^{\mathrm{h}}$, László Gajdán ${ }^{\mathrm{h}}$, József Hamvas ${ }^{\mathrm{i}}$, Mária Papp ${ }^{\mathrm{j}}$, Ildikó Földi ${ }^{\mathrm{j}}$, Krisztina Eszter Fehér ${ }^{\mathrm{j}}$, Márta Varga ${ }^{\mathrm{k}}$, Klára Csefkó ${ }^{\mathrm{k}}$, Imola Török ${ }^{1}$, Hunor Pál Farkas ${ }^{\mathrm{m}}$, Artautas Mickevicius ${ }^{\mathrm{n}}$, Elena Ramirez Maldonado ${ }^{\circ}$, Ville Sallinen ${ }^{\mathrm{p}}$, q, János Novák ${ }^{\mathrm{r}}$, Ali Tüzün Ince ${ }^{\mathrm{s}}$, Shamil Galeev ${ }^{\mathrm{t}}$, Barnabás Bod ${ }^{\mathrm{u}}$, János Sümegi v, Petr Pencik ${ }^{\text {w }}$, Zsolt Dubravcsik ${ }^{\mathrm{x}}$, Dóra Illés ${ }^{\mathrm{g}}$, Szilárd Gódi ${ }^{\mathrm{y}}$, Balázs Kui ${ }^{\mathrm{g}}$, Katalin Márta ${ }^{\mathrm{b}}$, Dániel Pécsi ${ }^{\mathrm{b}}$, Péter Varjú b, f, Zsolt Szakács b', Erika Darvasi ${ }^{\mathrm{e}}$, Andrea Párniczky b, c, z, 1, **, Péter Hegyi b, e, y, aa, 1, * on behalf of the Hungarian Pancreatic Study Group

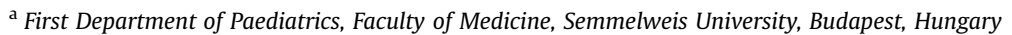

b Institute for Translational Medicine, Szentágothai Research Center, Medical School, University of Pécs, Pécs, Hungary

${ }^{c}$ Doctoral School of Theoretical Medicine, Faculty of Medicine, University of Szeged, Szeged, Hungary

${ }^{\mathrm{d}}$ Institute of Bioanalysis, Medical School, University of Pécs, Pécs, Hungary

e Centre for Translational Medicine, First Department of Medicine, Faculty of Medicine, University of Szeged, Szeged, Hungary

${ }^{\mathrm{f}}$ First Department of Medicine, Medical School, University of Pécs, Pécs, Hungary

${ }^{g}$ First Department of Medicine, Faculty of Medicine, University of Szeged, Szeged, Hungary

${ }^{\mathrm{h}}$ Szent György Teaching Hospital of County Fejér, Székesfehérvár, Hungary

i Bajcsy-Zsilinszky Hospital, Budapest, Hungary

${ }^{\mathrm{j}}$ Department of Internal Medicine, Division of Gastroenterology, Faculty of Medicine, University of Debrecen, Debrecen, Hungary

${ }^{\mathrm{k}}$ Department of Gastroenterology, Dr. Réthy Pál Hospital of County Békés, Békéscsaba, Hungary

${ }^{1}$ County Emergency Clinical Hospital, George Emil Palade University of Medicine, Pharmacy, Sciences and Technology of Târgu Mureș, Târgu Mureș,

Romania

$\mathrm{m}$ George Emil Palade University of Medicine, Pharmacy, Sciences and Technology of Târgu Mureș, Târgu Mureș, Romania

${ }^{\mathrm{n}}$ Vilnius University Hospital Santaros Clinics, Clinics of Abdominal Surgery, Nephrourology and Gastroenterology, Faculty of Medicine, Vilnius University,

Vilnius, Lithuania

${ }^{\circ}$ Consorci Sanitari Del Garraf, Sant Pere de Ribes, Barcelona, Spain

p Department of Transplantation and Liver Surgery, University of Helsinki and Helsinki University Hospital, Helsinki, Finland

${ }^{\mathrm{q}}$ Department of Abdominal Surgery, University of Helsinki and Helsinki University Hospital, Helsinki, Finland

r Pándy Kálmán Hospital of County Békés, Gyula, Hungary

${ }^{\mathrm{s}}$ Hospital of Bezmialem Vakif University, School of Medicine, Istanbul, Turkey

${ }^{t}$ Saint Luke Clinical Hospital, St. Petersburg, Russia

" Dr. Bugyi István Hospital, Szentes, Hungary

${ }^{v}$ Borsod-Abaúj-Zemplén County Hospital and University Teaching Hospital, Miskolc, Hungary

w Centrum Péce o Zažívací Trakt, Vítkovická Nemocnice a.s., Ostrava, Czech Republic

× Department of Gastroenterology, Bács-Kiskun County Hospital, Kecskemét, Hungary

${ }^{y}$ Division of Translational Medicine, First Department of Medicine, Medical School, University of Pécs, Pécs, Hungary

${ }^{z}$ Department of Gastroenterology, Heim Pál Children's Hospital, Budapest, Hungary

aa Hungarian Academy of Sciences-University of Szeged, Momentum Gastroenterology Multidisciplinary Research Group, Szeged, Hungary

\footnotetext{
* Corresponding author. 2nd floor, 12 Szigeti Road, Pécs, 7624, Hungary. PO BOX 99, Pécs, 7601, Hungary.

** Corresponding author. 2nd floor, 12 Szigeti Road, Pécs, 7624, Hungary. PO BOX 99, Pécs, 7601, Hungary.

E-mail addresses: a.parniczky@tm-centre.org (A. Párniczky), hegyi.peter@pte.hu (P. Hegyi).

1 Péter Hegyi and Andrea Párniczky (contributed equally).
} 
A R T I C L E I N F O

\section{Article history:}

Received 28 March 2020

Accepted 30 March 2020

Available online 10 April 2020

\section{Keywords:}

Acute pancreatitis

Hypertriglyceridemia

Etiology

Cohort

Severity

\begin{abstract}
A B S T R A C T
Background: Hypertriglyceridemia is the third most common cause of acute pancreatitis (AP). It has been shown that hypertriglyceridemia aggravates the severity and related complications of AP; however, detailed analyses of large cohorts are contradictory. Our aim was to investigate the dose-dependent effect of hypertriglyceridemia on AP.

Methods: AP patients over 18 years old who underwent triglyceride measurement within the initial three days were included into our cohort analysis from a prospective international, multicenter AP registry operated by the Hungarian Pancreatic Study Group. Data on 716 AP cases were analyzed. Six groups were created based on the highest triglyceride level $(<1.7 \mathrm{mmol} / \mathrm{l}, 1.7-2.19 \mathrm{mmol} / \mathrm{l}, 2.2$ -5.59 mmol/1, 5.6-11.29 mmol/1, 11.3-22.59 mmol/l, $\geq 22.6 \mathrm{mmol} / \mathrm{l})$.

Results: Hypertriglyceridemia ( $\geq 1.7 \mathrm{mmol} / \mathrm{l}$ ) presented in $30.6 \%$ of the patients and was significantly and dose-dependently associated with younger age and male gender. In $7.7 \%$ of AP cases, hypertriglyceridemia was considered as a causative etiological factor ( $\geq 11.3 \mathrm{mmol} / \mathrm{l}$ ); however, $43.6 \%$ of these cases were associated with other etiologies (alcohol and biliary). Hypertriglyceridemia was significantly and dose-dependently related to obesity and diabetes. The rates of local complications and organ failure and maximum CRP level were significantly and dose-dependently raised by hypertriglyceridemia. Triglyceride above $11.3 \mathrm{mmol} / \mathrm{l}$ was linked to a significantly higher incidence of moderately severe AP and longer hospital stay, whereas triglyceride over $22.6 \mathrm{mmol} / \mathrm{l}$ was significantly associated with severe AP as well.

Conclusion: Hypertriglyceridemia dose-dependently aggravates the severity and related complications of AP. Diagnostic workup for hypertriglyceridemia requires better awareness regardless of the etiology of AP.

(C) 2020 IAP and EPC. Published by Elsevier B.V. This is an open access article under the CC BY license (http://creativecommons.org/licenses/by/4.0/).
\end{abstract}

\section{Introduction}

Hypertriglyceridemia (HTG) affects $10-30 \%$ of the general adult population [1,2]. Classifying HTG is complex; both genetic (primary) and environmental (secondary) factors can lead to an elevated triglyceride (TG) level. In rare cases ( $2 \%$ ), primary severe HTG (TG $\geq 10 \mathrm{mmol} / \mathrm{l}$ ) may arise as a result of autosomal recessive, monogenic familial chylomicronemia syndrome (FCS, former Type I). However, a majority of severe HTG cases are multifactorial and have polygenic (mixed HTG, former Type V) determinants with additional secondary factors. Mild-to-moderate HTG cases (2-9.9 mmol/l TG) are similarly polygenic with complex genetic susceptibility (former Type IV, Type IIB and Type III) [2-4]. As regards environmental factors, alcohol, positive-energy balanced diet, obesity, uncontrolled diabetes mellitus (DM), renal diseases, pregnancy, hypothyroidism and medications (e.g., estrogen, retinoids, thiazides, and b-blockers) were shown to be responsible for a raised TG level usually with the interaction of genetic susceptibility $[5,6]$.

HTG is the third most common cause of acute pancreatitis (AP), and it is responsible for up to $15 \%$ of AP cases [7-9]. According to the definition, the majority of experts agree that AP related to TG above $5.6 \mathrm{mmol} / \mathrm{l}$ should be considered as suspected hypertriglyceridemia-induced acute pancreatitis (HTG-AP) and AP associated with TG over $11.3 \mathrm{mmol} / \mathrm{l}$ is confirmed as HTG-AP [4,10]. Importantly, the occurrence of AP increases with the increase in TG level. There is a $5 \%$ possibility of developing AP if TG exceeds $11.3 \mathrm{mmol} / \mathrm{l}$, and it rises to $10-20 \%$ if TG elevates over $22.6 \mathrm{mmol} / \mathrm{l}$ [4]. HTG-AP is of great importance for several reasons: 1) it has shown a rising incidence worldwide as a result of increasing obesity-related dyslipidemia [11,12]; 2) it raises the risk of severe AP and related complications [8,10,12-16]; and 3) there is no evidence-based therapy for it [17-19].

We aimed to perform a cohort analysis for investigating the dose-dependent effect of HTG on AP and providing data for further prospective randomized clinical trials. In our current cohort study, we show clear evidence that TG level dose-dependently worsens the outcome of AP. The rate of local complications is significantly higher above $5.6 \mathrm{mmol} / \mathrm{l}$, whereas significantly elevated organ failure presents above $11.3 \mathrm{mmol} / \mathrm{l} \mathrm{TG}$ level, strongly suggesting that TG-lowering therapy can achieve a better outcome of AP at a much lower TG level than we previously thought.

\section{Methods}

AP patients ( $n=1435$ ) over 18 years old were enrolled in the prospectively collected international, multicenter AP registry operated by the Hungarian Pancreatic Study Group (HPSG) between 2012 and 2017. Post-hoc cohort analysis was performed on 716 AP cases who underwent TG measurement within $72 \mathrm{~h}$ from admission. AP was diagnosed based on the International Association of Pancreatology/American Pancreatic Association (IAP/APA) and HPSG evidence-based guidelines [17,18]. Participating countries are shown in Sup. Fig. 1.

The threshold of the normal TG value was determined at $1.7 \mathrm{mmol} / \mathrm{l}[6]$. Six groups were established based on the Endocrine Society Clinical Practice Guideline and previously published clinical data related to HTG-AP [4,6]: Group 1: $<1.7 \mathrm{mmol} / \mathrm{l}$; Group 2: 1.7-2.19 mmol/l; Group 3: 2.2-5.59 mmol/l; Group 4: 5.6-11.29 mmol/1; Group 5: $11.3-22.59 \mathrm{mmol} / \mathrm{l}$; and Group 6: $\geq 22.6 \mathrm{mmol} / \mathrm{l}$. To convert TG from $\mathrm{mmol} / \mathrm{l}$ to $\mathrm{mg} / \mathrm{dl}$ multiply by 88.57. In case of each variable, elevated TG groups (Groups 2-6) were compared with the normal TG group (Group 1). TG categories were collapsed to three groups ( $<1.7 \mathrm{mmol} / \mathrm{l} ; 1.7-11.29 \mathrm{mmol} / \mathrm{l}$; $\geq 11.3 \mathrm{mmol} / \mathrm{l}$ ) for the analysis of organ failure because of the low event number.

Seventy-three variables were collected from each AP case as listed in Table S1. The analysis was performed on 42,655/52,268 available data. Local complications, organ failure and severity were defined based on the revised Atlanta classification [20]. The 716 cases investigated have shown the same epidemiological and major outcome distribution as the total cohort (1435 cases), demonstrating that our patients' population represents a normal AP cohort (Sup. Fig. 2).

The registry received ethical permission from the Scientific and Research Ethics Committee of the Medical Research Council 
(22254-1/2012/EKU) in 2012, and all the patients provided written informed consent to participate. The study protocol conforms to the ethical guidelines of the Declaration of Helsinki updated in 2013 as reflected in a priori approval by the institution's human research committee.

\section{Statistical analysis}

Prior to analysis of the dataset, descriptive statistical tools were used to describe the basic characteristics. Mean and standard error of the mean were calculated for continuous variables, whereas the incidence in each group was determined for categorical variables. Depending on the distribution of the data, the independent Student's t-test or Mann-Whitney $U$ test was used to evaluate differences between continuous parameters. The chi-square test or Fisher's exact test was conducted to analyze the relations between the variables. We compared the confidence intervals $(\mathrm{CI})$ of the proportions to investigate differences in the incidence of moderately severe cases between groups. A p-value less than $0.05(\leq 0.05)$ was determined as statistically significance. All analyses were performed using IBM-SPSS Statistical Software Version 25 (IBM Corporation, Armonk, NY, USA).

\section{Results}

In our cohort, $30.6 \%(n=219)$ of the patients presented with elevated TG level ( $\geq 1.7 \mathrm{mmol} / \mathrm{l})$. HTG was significantly and dosedependently linked to younger age and male gender (Fig. 1A-C). In $7.7 \%$ of AP cases $(n=55)$, TG level was above $11.3 \mathrm{mmol} / \mathrm{l}$, which is considered as a causative etiological factor [6,10]. In $56.4 \%$ of these cases, HTG-AP patients had no other etiology described; however, raised TG level was also accompanied by alcohol in $38.2 \%$ of these cases and by biliary etiology in 5.4\%, showing that HTG-AP is associated with other etiologies in a substantial number of cases (Fig. 1D).

Data from patients' medical history revealed that HTG is significantly and dose-dependently linked to obesity and DM (Fig. 2B and C); however, there is no relation to chronic pancreatitis (CP) and the Charlson comorbidity index (CCI) [21] (Fig. 2A and D). The amount of previous AP in the medical history was higher in the HTG group compared to the normal TG group (Fig. 2A). General symptoms of AP and physical examination on admission (incidence, duration and intensity of pain, nausea, vomiting, abdominal tenderness and guarding, and blood pressure) have not shown a significant link to elevated TG level (Fig. 3A and B). However, HTG was significantly related to increased heart rate (Fig. 3C). As regards the laboratory parameters on admission showing significant differences with HTG, amylase, lipase, sodium, and calcium were associated inversely; however, glucose, C-reactive protein (CRP), cholesterol, red blood cell count (RBC), hemoglobin, and hematocrit were related parallel with TG level (Fig. 4). On admission laboratory parameters consistent with cholestasis suggested that HTG is less
A

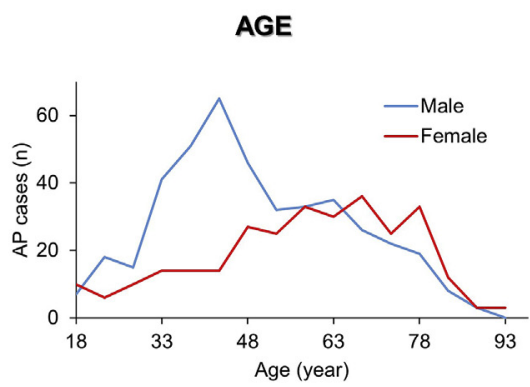

C

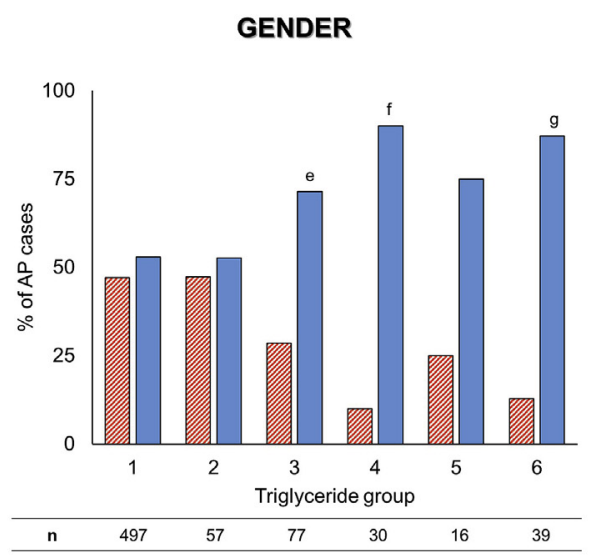

四Female $\square$ Male
B

\begin{tabular}{cccc|c}
\hline Group & $\begin{array}{c}\text { Triglyceride } \\
(\mathrm{mmol} / \mathrm{l})\end{array}$ & $\mathbf{n}$ & $\%$ & $\begin{array}{c}\text { Age } \\
\text { year (SE) }\end{array}$ \\
\hline 1 & $<1.7$ & 497 & 69.4 & $57.0(0.8)$ \\
\multicolumn{2}{c}{ NORMAL TG } & 497 & 69.4 & $\mathbf{5 7 . 0}(\mathbf{0 . 8})$ \\
\hline 2 & $1.7-2.19$ & 57 & 8.0 & $55.1(1.9)$ \\
3 & $2.2-5.59$ & 77 & 10.8 & $50.1(1.6)^{\mathrm{a}}$ \\
4 & $5.6-11.29$ & 30 & 4.2 & $49.4(2.3)^{\mathrm{b}}$ \\
$\mathbf{5}$ & $11.3-22.59$ & 16 & 2.2 & $50.2(3.0)$ \\
$\mathbf{6}$ & $\geq 22.6$ & 39 & 5.4 & $43.6(1.5)^{\mathrm{c}}$ \\
ELEVATED TG & $\mathbf{2 1 9}$ & $\mathbf{3 0 . 6}$ & $\mathbf{5 0 . 1 ( 0 . 9 ) ^ { \mathrm { d } }}$ \\
\hline \multicolumn{2}{c}{ TOTAL } & $\mathbf{7 1 6}$ & $\mathbf{1 0 0}$ & $\mathbf{5 4 . 9 ( 0 . 6 )}$ \\
\hline
\end{tabular}

D
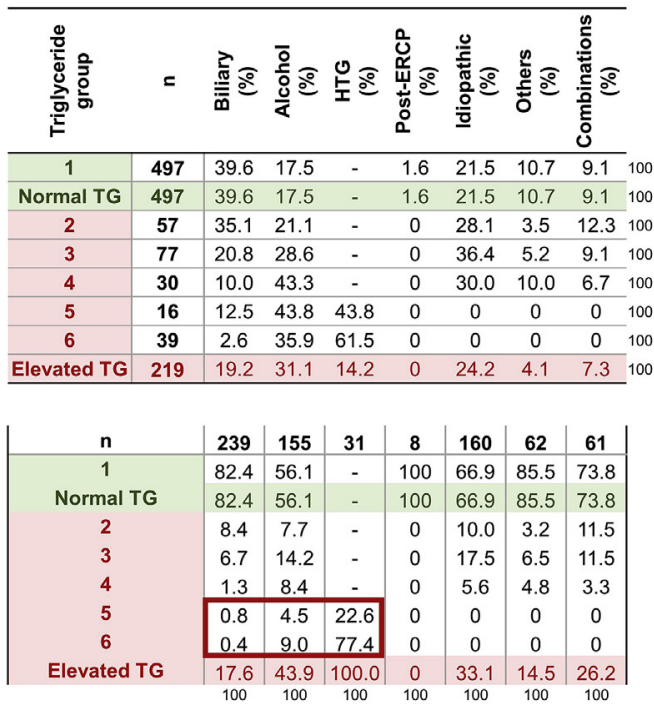

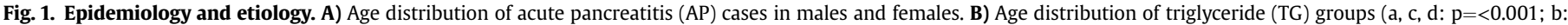

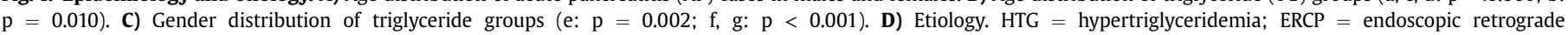
cholangiopancreatography. 
A

\begin{tabular}{cccc}
\hline Group & $\begin{array}{c}\text { Triglyceride } \\
(\mathbf{m m o l} / \mathrm{l})\end{array}$ & $\begin{array}{c}\text { AP } \\
\%(\mathrm{n})\end{array}$ & $\begin{array}{c}\text { CP } \\
\%(\mathrm{n})\end{array}$ \\
\hline 1 & $<1.7$ & $22.3(475)$ & $6.1(475)$ \\
\hline 2 & $1.7-2.19$ & $25.9(54)$ & $7.4(54)$ \\
3 & $2.2-5.59$ & $34.2^{\mathrm{a}}(73)$ & $0^{\mathrm{b}}(73)$ \\
4 & $\mathbf{5 . 6 - 1 1 . 2 9}$ & $33.3(27)$ & $0(27)$ \\
5 & $\mathbf{1 1 . 3 - 2 2 . 5 9}$ & $18.8(16)$ & $6.3(16)$ \\
6 & $\geq 22.6$ & $33.3(36)$ & $0(36)$ \\
\hline
\end{tabular}

C
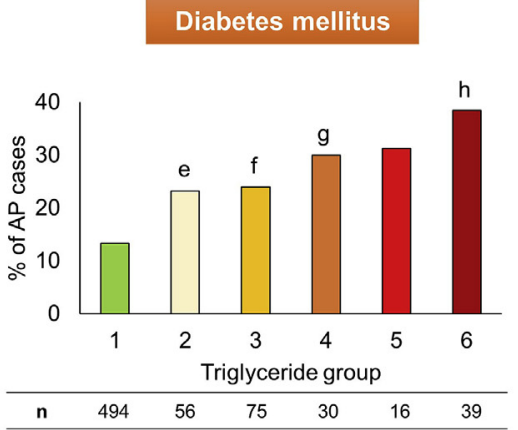

B

Obesity

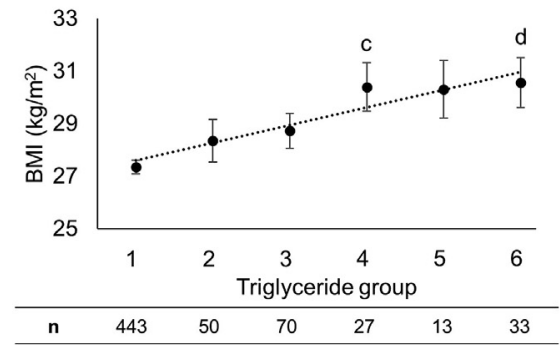

D

$\mathrm{CCl}$

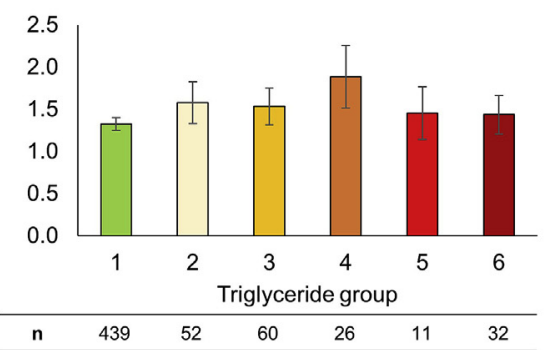

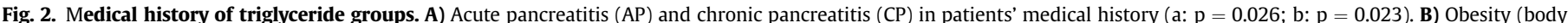

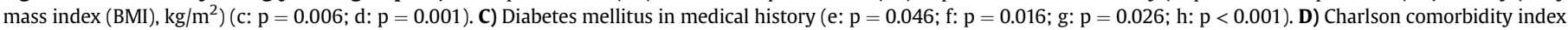
$(\mathrm{CCI}) \mathrm{N}$ numbers $(\mathrm{n})$ indicate the total number of cases in each triglyceride group.

\begin{tabular}{|c|c|c|c|c|c|c|c|c|}
\hline \multirow[b]{2}{*}{ Group } & \multirow[b]{2}{*}{$\begin{array}{c}\text { Triglyceride } \\
(\mathrm{mmol} / \mathrm{l})\end{array}$} & \multicolumn{3}{|c|}{ Abdominal pain } & \multirow[b]{2}{*}{$\begin{array}{c}\text { Nausea } \\
\%(n)\end{array}$} & \multirow[b]{2}{*}{$\begin{array}{l}\text { Vomiting } \\
\quad \%(n)\end{array}$} & \multirow[b]{2}{*}{$\begin{array}{c}\text { Abdominal } \\
\text { tenderness } \\
\%(n)\end{array}$} & \multirow[b]{2}{*}{$\begin{array}{c}\text { Abdominal } \\
\text { guarding } \\
\%(n)\end{array}$} \\
\hline & & $\%(n)$ & $\begin{array}{c}\text { Duration before } \\
\text { admission } \\
\text { hour } \pm S E(n)\end{array}$ & $\begin{array}{l}\text { Intensity } \\
1-10 \pm S E(n)\end{array}$ & & & & \\
\hline 1 & $<1.7$ & $98.6(497)$ & $58.7 \pm 5.1(434)$ & $7.6 \pm 0.1(287)$ & $69.6(477)$ & $56.3(485)$ & $86.2(478)$ & $10.3(478)$ \\
\hline \multicolumn{2}{|c|}{ NORMAL TG } & 98.6 & $58.7 \pm 5.1$ & $7.6 \pm 0.1$ & 69.6 & 56.3 & 86.2 & 10.3 \\
\hline 2 & $1.7-2.19$ & $98.2(57)$ & $37.7 \pm 7.1(46)$ & $7.8 \pm 0.4(27)$ & $79.2(53)$ & $58.2(55)$ & $81.5(54)$ & $11.1(54)$ \\
\hline 3 & $2.2-5.59$ & $100(77)$ & $50.8 \pm 15.1^{a}(67)$ & $7.7 \pm 0.3(42)$ & $66.7(72)$ & $46.7(75)$ & $87.8(74)$ & $12.2(74)$ \\
\hline 4 & $5.6-11.29$ & $100(30)$ & $31.6 \pm 7.6(26)$ & $7.8 \pm 0.3(17)$ & $76.7(30)$ & $60.0(30)$ & $100^{\mathrm{b}}(27)$ & $14.8(27)$ \\
\hline 5 & $11.3-22.59$ & $100(16)$ & $32.5 \pm 7.8(15)$ & $8.0 \pm 0.5(8)$ & $62.5(16)$ & $50.0(16)$ & $100(16)$ & $13.3(15)$ \\
\hline 6 & $\geq 22.6$ & $100(39)$ & $49.0 \pm 21.5(33)$ & $7.7 \pm 0.5(19)$ & $61.1(36)$ & $45.9(37)$ & $89.2(37)$ & $10.8(37)$ \\
\hline \multicolumn{2}{|c|}{ ELEVATED TG } & 99.5 & $43.1 \pm 6.9$ & $7.8 \pm 0.2$ & 70.0 & 51.6 & 88.9 & 12.1 \\
\hline
\end{tabular}

B

Blood pressure

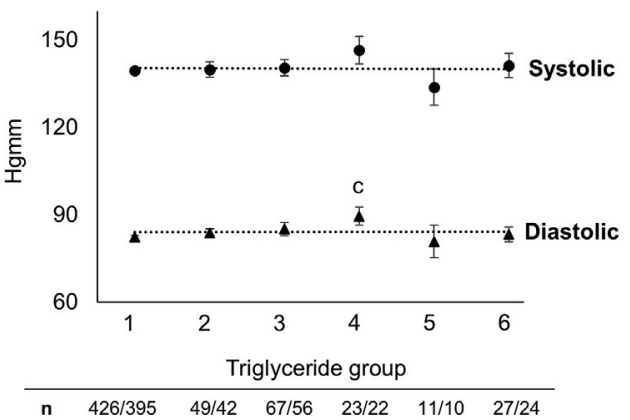

C Heart rate

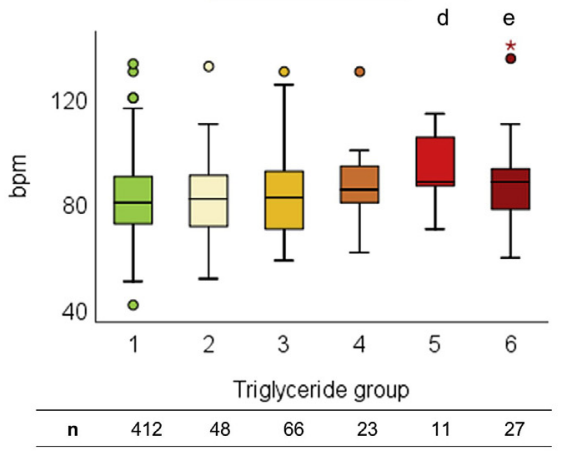

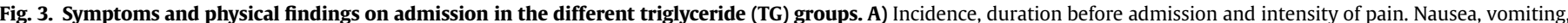

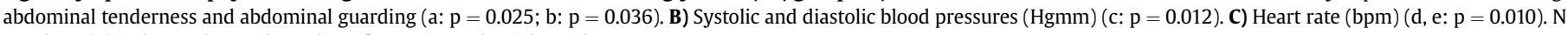
numbers $(\mathrm{n})$ indicate the total number of cases in each triglyceride group.

common in cases with biliary etiology. (Sup. Fig. 3). The parallel rise in gamma-glutamyltransferase $(\gamma \mathrm{GT})$ and TG levels confirms that alcohol consumption is linked to HTG (Sup. Fig. 3D). White blood cell count (WBC), thrombocyte, lactate dehydrogenase (LDH), blood urea nitrogen (BUN), creatinine, and potassium had no significant relation to HTG (Sup. Fig. 4). 


\begin{tabular}{|c|c|}
\hline Group & $\begin{array}{c}\text { Triglyceride } \\
(\text { mmol/I) }\end{array}$ \\
\hline 1 & $<1.7$ \\
\hline 2 & $1.7-2.19$ \\
3 & $2.2-5.59$ \\
4 & $5.6-11.29$ \\
5 & $11.3-22.59$ \\
6 & $\geq 22.6$ \\
\hline
\end{tabular}

B
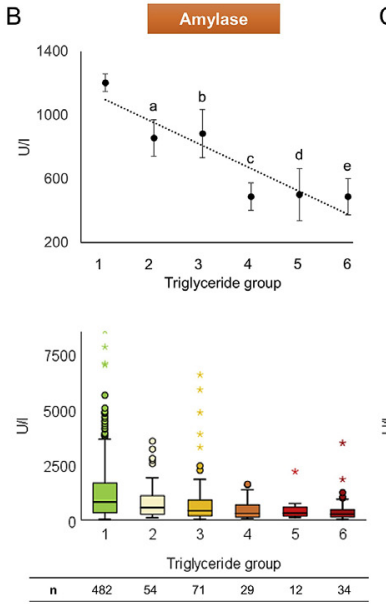

C
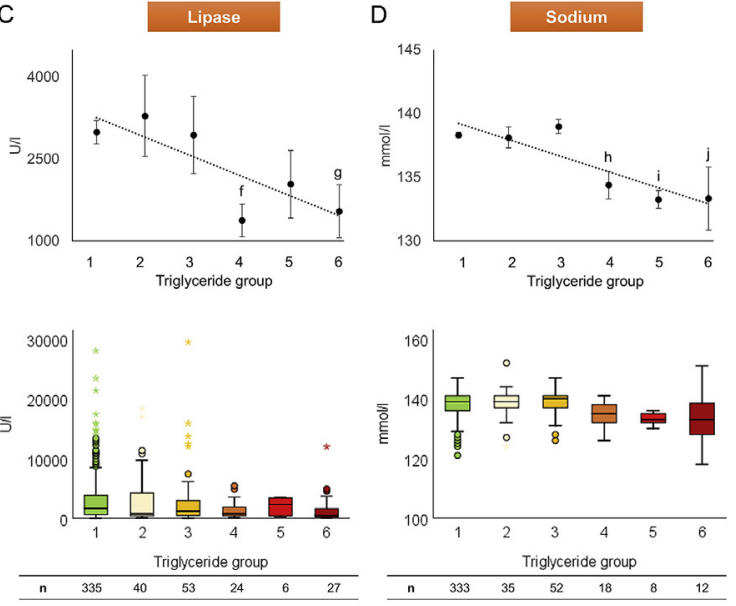

D Sodium

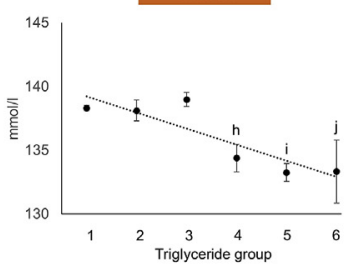

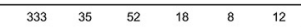

E
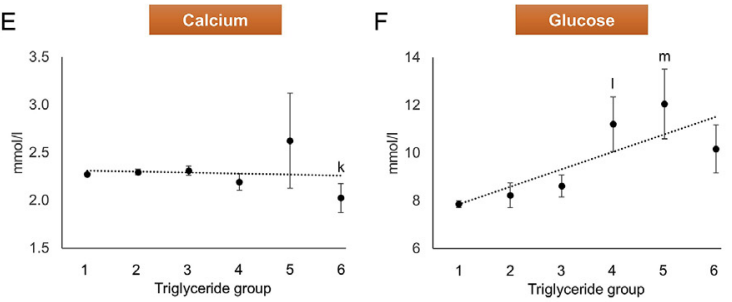

G
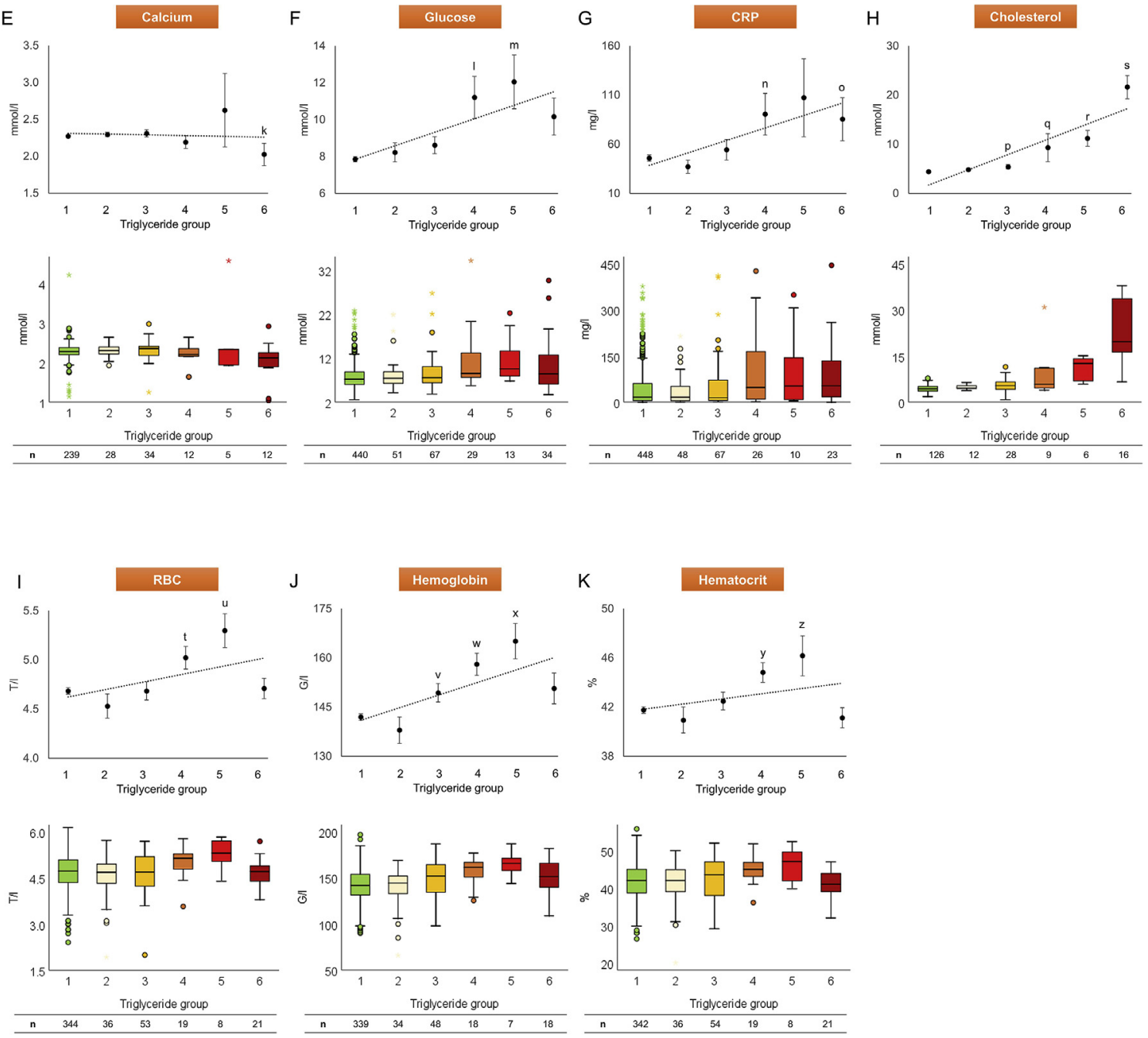

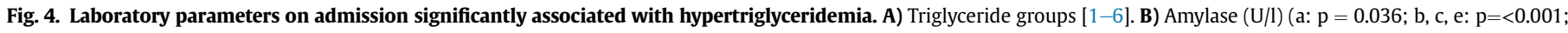

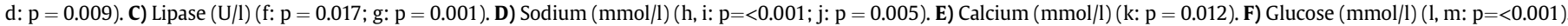

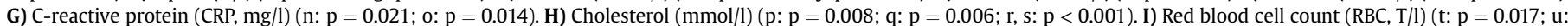

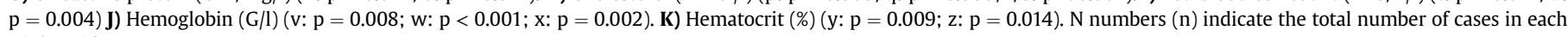
triglyceride group. 
The rate of local complications, including peripancreatic fluid collection, pancreatic necrosis and DM, was significantly and dosedependently increased with TG level (Fig. 5B-E); however, pancreatic pseudocysts did not show significant differences between the investigated groups above $2.2 \mathrm{mmol} / \mathrm{l}$ (Fig. 5F). Organ failure, including heart and renal failure, and maximum CRP level were significantly and dose-dependently raised by TG level (Fig. 6B, D-G); however maximum WBC has not shown any significant differences by HTG (Fig. 6C).

As regards severity, TG level above $11.3 \mathrm{mmol} / \mathrm{l}$ was associated with a significantly higher rate of moderately severe AP and longer hospital stay, whereas TG level above $22.6 \mathrm{mmol} / \mathrm{l}$ was significantly related to severe AP as well (Fig. 7A and B). Due to the low event rate, the effect of HTG on mortality could not be determined (Fig. 7A). Detailed values of charts and statistical parameters are shown in Tables S2 and S3.

Plasmapheresis was carried out in $36.4 \%$ (20/55) of the HTG-AP cases; $85 \%$ of these patients had an initial TG level higher than $22.6 \mathrm{mmol} / \mathrm{l}$ and the average TG level was $70.1 \pm 10.0 \mathrm{mmol} / \mathrm{l}$.

\section{Discussion}

HTG-AP has grown in incidence and importance. According to the previously published literature [7,9], HTG is the third most common cause of AP (7.7\%). However, it seems more than likely that the incidence of HTG-AP is higher than is usually recorded. The prospective multicenter, international AP cohort run by the HPSG revealed that TG measurement is performed in just 50\% (716/1435) of AP cases within the first three days from admission and most probably this rate is even worse in centers which provide no data. Furthermore, our data also confirmed additional etiological factors (alcohol and biliary disease) besides HTG in $43.6 \%$ of HTG-AP cases and showed a dose-dependent relation between obesity (body mass index), pre-existing DM and HTG. These data also suggest a higher incidence rate since physicians finding an etiological factor behind AP usually stop further investigation. Our data are in accordance with Scherer et al. who recommend that HTG-AP should be suspected in the case of significant alcohol consumption, poorly controlled DM and metabolic syndrome, including obesity [4]. Although our data clearly show that biliary obstruction may be associated with HTG, serum TG was measured in just $44.3 \%$ (266/601) of the biliary AP cases. Furthermore, in the case of biliary AP, there is no recommendation for TG measurement.

Our data analysis confirmed results published by Zheng et al. [12] and Zhu et al. [8] which show that HTG is significantly linked to younger age and male gender. This is not surprising, since underlying genetic abnormalities behind HTG contribute to younger manifestation and alcohol-related HTG affects male gender and younger age more [3,4,22]. In contrast, biliary etiology is accompanied by a higher rate for female gender and older population $[3,23]$.

Diagnosing AP in the presence of HTG can be challenging due to in vitro interference between plasma TG level above $5.6 \mathrm{mmol} / \mathrm{l}$ (with grossly turbid plasma) and determination of amylase and lipase activities [24,25]. Our data confirmed a significant reduction of amylase and lipase levels with the elevation of TG. Furthermore, case reports have been published by Singh et al. [26] and Sotello et al. [27], presenting HTG-AP patients with normal amylase and lipase levels.

Our analysis has shown that local complications and organ failure were significantly increased by HTG, just as published in previous reports and a recent meta-analysis by Kiss et al. $[10,13,15,28,29]$. Nawaz et al. [30] confirmed that TG above $2.3 \mathrm{mmol} / \mathrm{l}$ is independently associated with persistent organ failure on a multivariate analysis controlling for age, gender, body mass index, diabetes, and alcohol etiology, whereas Szentesi et al. [31] revealed that hyperlipidemia was an independent predictive factor for local complications and new-onset DM. Although we could not confirm a significantly higher risk of pancreatic pseudocysts in the case of TG above $2.2 \mathrm{mmol} / \mathrm{l}$, it is well known that pseudocysts usually occur more than four weeks after the onset of $\mathrm{AP}$ and the average hospital stay was $10.4 \pm 0.3$ days in our cohort [20].

Based on our data analysis, severity of AP and length of hospitalization were significantly increased by HTG $[8,10,12,13,29,30,32]$. Navarro et al. [33] and Goyal et al. [34] also confirmed that HTG
A

\begin{tabular}{|c|c|}
\hline Group & $\begin{array}{c}\text { Triglyceride } \\
(\mathrm{mmol} / \mathrm{l})\end{array}$ \\
\hline 1 & $<1.7$ \\
\hline 2 & $1.7-2.19$ \\
3 & $2.2-5.59$ \\
4 & $5.6-11.29$ \\
5 & $11.3-22.59$ \\
6 & $\geq 22.6$ \\
\hline
\end{tabular}

D

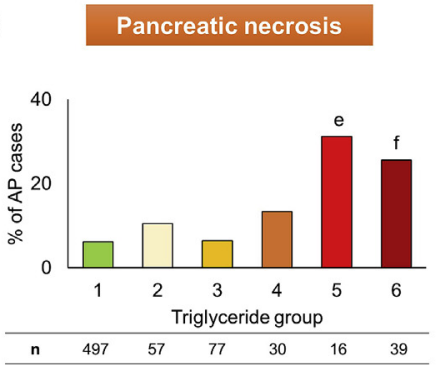

B

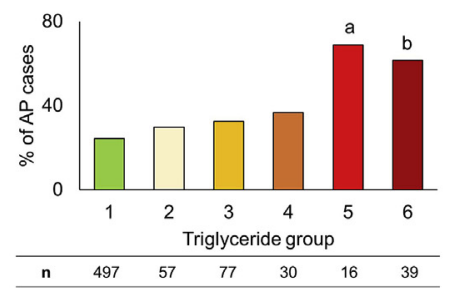

E

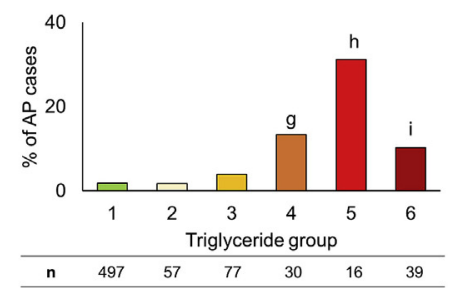

Peripancreatic fluid collection

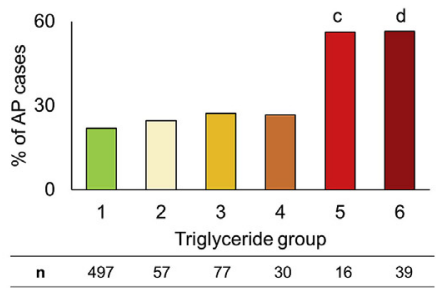

F Pancreatic pseudocyst

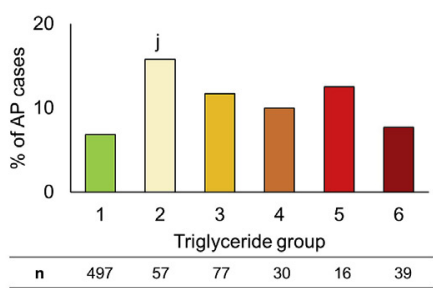

Fig. 5. Local pancreatic complications in the different triglyceride groups. A) Triglyceride groups [1-6]. B) Local pancreatic complications (a, b: $p<0.001$ ). C) Peripancreatic fluid collection (c: $p=0.004$; $\mathrm{d}: \mathrm{p}<0.001$ ). D) Pancreatic necrosis (e: $\mathrm{p}=0.003$; f: $\mathrm{p}<0.001$ ). E) Diabetes mellitus as complication (g: $\mathrm{p}=0.004 ; \mathrm{h}: \mathrm{p}<0.001 ; \mathrm{i}: \mathrm{p}=0.011$ ). F) Pancreatic pseudocyst $(\mathrm{j}: \mathrm{p}=0.031)$. $\mathrm{N}$ numbers $(\mathrm{n})$ indicate the total number of cases in each triglyceride group. 

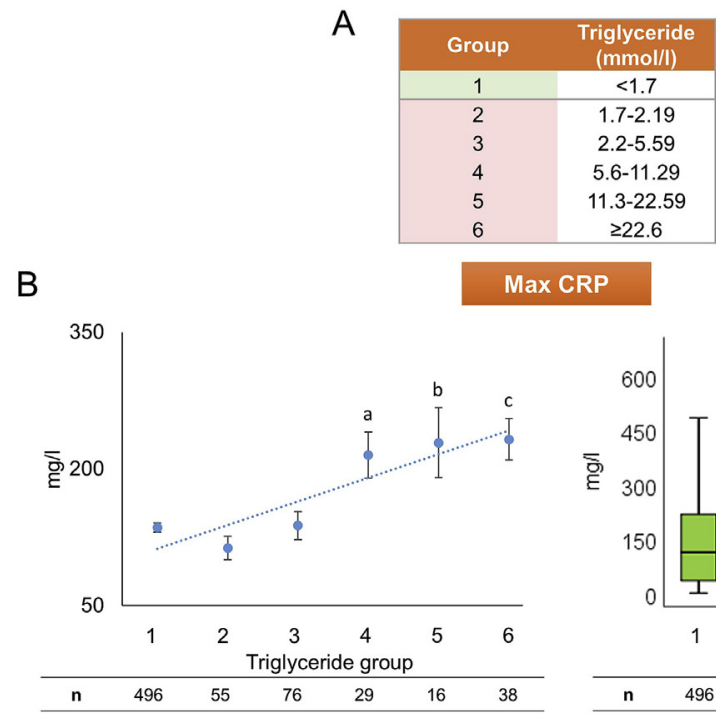

Max CRP

C

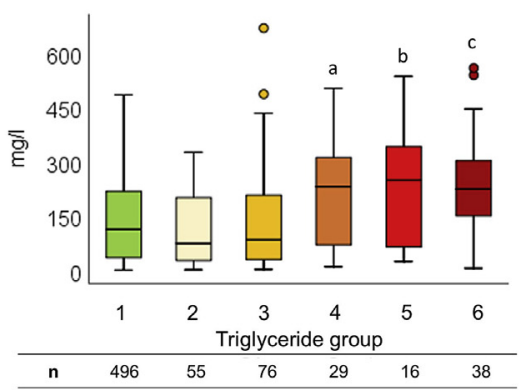

Max WBC
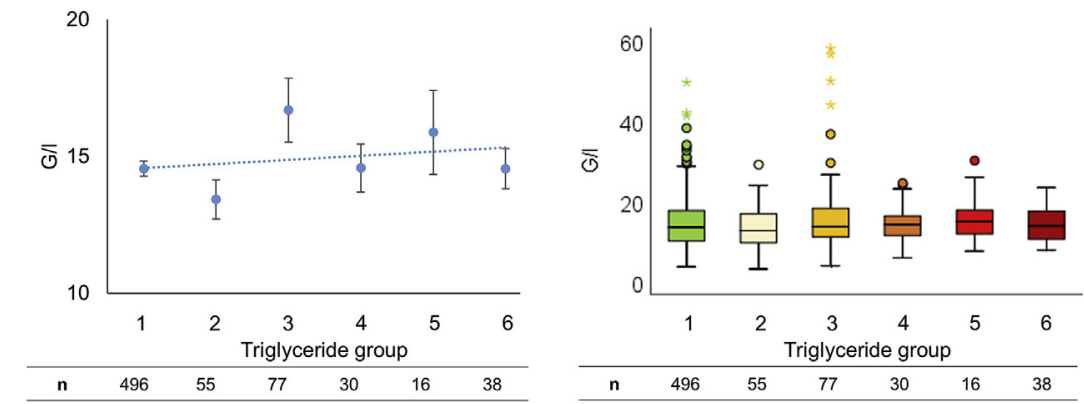

D

Organ failure

E

Respiratory failure
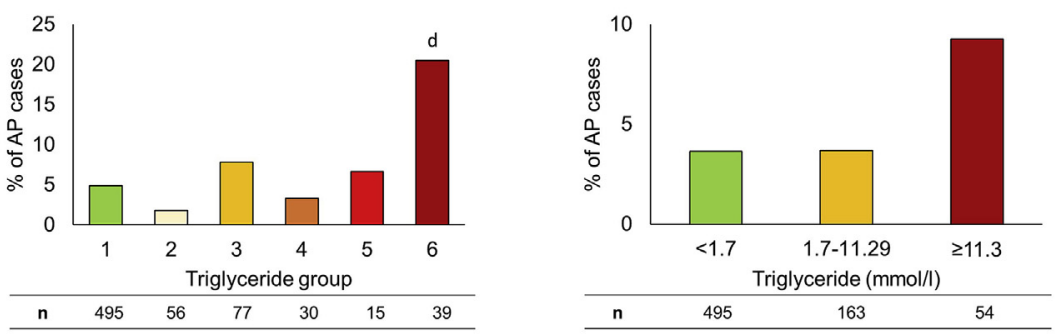

$\mathrm{F}$

Heart failure

G
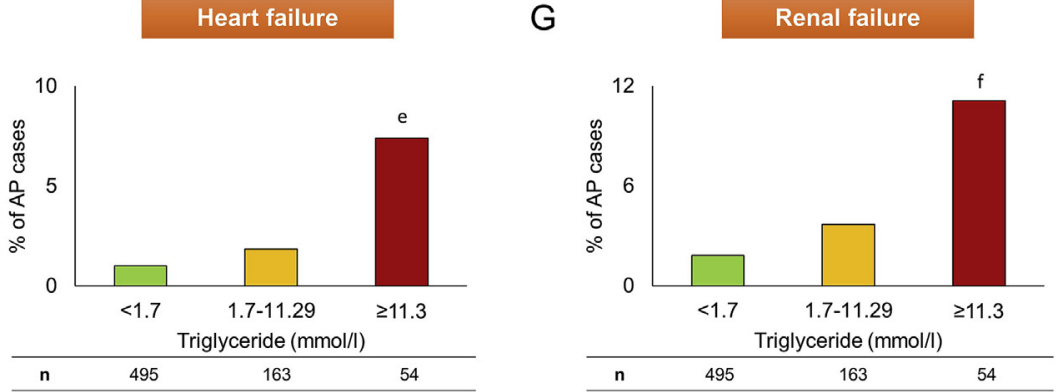

Fig. 6. Systemic inflammatory effect and organ failure in the different triglyceride groups. A) Triglyceride groups [1-6]. B) Maximum C-reactive protein (Max CRP, mg/l) (a, $C$ : $\mathrm{p}<0.001 ; \mathrm{b}: \mathrm{p}=0.029)$. C) Maximum white blood cell count (Max WBC, G/l). D) Organ failure (d: $\mathrm{p}=0.001$ ). E) Respiratory failure. F) Heart failure (e: $\mathrm{p}=0.007) . \mathbf{G})$ Renal failure (f: $\mathrm{p}=0.002)$. $\mathrm{N}$ numbers $(\mathrm{n})$ indicate the total number of cases in each triglyceride group.

aggravates the severity of AP compared to biliary and alcoholic etiology, respectively. The underlying mechanism is clearly complex. Unsaturated free fatty acids (UFAs) generated from TG are responsible for cell injury by membrane lipid peroxidation, longlasting cytosolic $\mathrm{Ca}^{2+}$ elevation and mitochondrial damage $[35,36]$. In the case of additional alcohol consumption, non- 
A

\begin{tabular}{cccc}
\hline Group & $\begin{array}{c}\text { Triglyceride } \\
(\mathrm{mmol} / \mathrm{l})\end{array}$ & $\begin{array}{c}\text { LOH } \\
\text { day } \pm \text { SE }(\mathrm{n})\end{array}$ & $\begin{array}{c}\text { Mortality } \\
\text { event } \mathrm{n}(\mathrm{n})\end{array}$ \\
\hline $\mathbf{1}$ & $<1.7$ & $10.1 \pm 0.3(497)$ & $8(496)$ \\
NORMAL TG & $10.1 \pm 0.3$ & 8 \\
\hline 2 & $1.7-2.19$ & $10.4 \pm 1.2(57)$ & $0(56)$ \\
3 & $2.2-5.59$ & $9.7 \pm 1.1(77)$ & $1(77)$ \\
4 & $5.6-11.29$ & $10.1 \pm 1.4(30)$ & $1(30)$ \\
5 & $11.3-22.59$ & $13.1 \pm 1.9^{\mathrm{a}}(16)$ & $0(15)$ \\
6 & $\geq 22.6$ & $14.3 \pm 2.1^{\mathrm{b}}(39)$ & $1(38)$ \\
ELEVATED TG & $\mathbf{1 1 . 0 \pm 0 . 7}$ & 3 \\
\hline \multicolumn{2}{c}{ TOTAL } & $\mathbf{1 0 . 4 \pm 0 . 3}$ & $\mathbf{1 1}$ \\
\hline \multicolumn{5}{c}{}
\end{tabular}

B

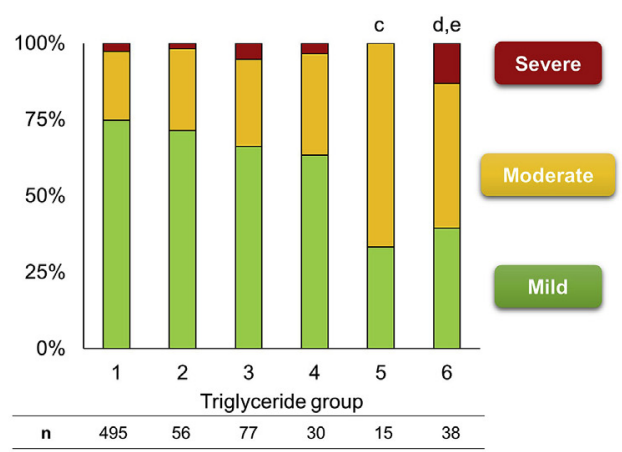

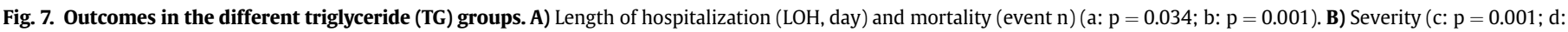

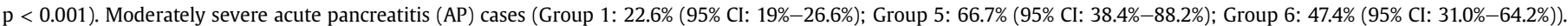
Severe AP cases (e: $\mathrm{p}=0.006)$. $\mathrm{N}$ numbers $(\mathrm{n})$ indicate the total number of cases in each triglyceride group.

oxidative ethanol metabolites (fatty acid ethyl esters, FAEEs) contribute to the persistent $\mathrm{Ca}^{2+}$ elevation and drop of ATP level $[37,38]$. Besides, the raised plasma viscosity caused by hyperchylomicronemia leads to ischemia and acidosis in the pancreatic capillaries [5]. This pathologic environment results in an early trypsinogen activation and pancreatic lipase leakage, leading to further free fatty acid (FFA) release and accumulation [5,35,39]. Moreover, UFAs bring about a systemic pro-inflammation by increased mRNA production of tumor necrosis factor-alpha (TNF- $\alpha$ ) and neutrophil chemoattractants, thereby increasing the severity of AP [36]. In our cohort, heart rate and maximum CRP were significantly raised by HTG, confirming the systemic inflammatory effect of relatively high TG level. In contrast, Pothoulakis et al. [40] and Balachandra et al. [41] reported that HTG does not worsen severity. Furthermore, Wang et al. showed that longer hospital stay was associated with higher TG level, but the difference was not significant [29].

The overall mortality of AP is $\sim 1 \%$ based on the literature $[3,12]$ and $1.5 \%$ in our cohort, but we could not perform a further subgroup analysis because of the low event number. Zhu et al. [8] and Deng et al. [42] confirmed that HTG-AP is accompanied by a significantly higher rate of mortality among severe AP cases compared to biliary AP and non-HTG etiology, respectively. However, Tai et al. [32] showed that mortality was similar in HTG-AP and biliary AP groups in a general AP cohort.

In our cohort, plasmapheresis was carried out in $36.4 \%$ of the HTG-AP cases. Although our data clearly suggest that the severity of AP is significantly elevated above $11.3 \mathrm{mmol} / \mathrm{l} \mathrm{TG}$ level, the average TG level was $70.1 \pm 10.0 \mathrm{mmol} / \mathrm{l}$ in patients with plasmapheresis and $85 \%$ of these cases had a TG level over $22.6 \mathrm{mmol} / \mathrm{l}$. We could not state any further conclusion regarding the therapy because of incomplete data and lack of randomization as a result of the cohort feature of the dataset. Overall, in most cases, TG-lowering therapy, such as plasmapheresis and glucose-heparin-insulin (GLU-HEPINS) administration, is performed above a TG level of $40 \mathrm{mmol} / \mathrm{l}$. In order to solve this unmet need, the HPSG has initiated a prospective randomized clinical trial to investigate different lipid-lowering therapies in AP [43].

Our study has several limitations. Although all data were collected prospectively, all questions were raised retrospectively. Cases were included into the analysis with TG measurement within the first three days from admission, but unfortunately still just 50\% of the entire cohort met the inclusion criteria. We attempted to minimize these limitations by comparing the epidemiological and major outcome distributions of the data analyzed and the whole cohort. We confirmed that the population under investigation represents a normal AP cohort.

\section{Conclusion}

Our results confirm that HTG dose-dependently increases the complications and severity of AP and highlights the necessity of better awareness of an accurate determination of causative and influencing risk factors in AP regardless of the etiology. Our data suggest that lipid-lowering therapy may be important clinically at a much lower TG level than we previously thought.

\section{Declaration of competing interest}

The authors declare that the research was conducted in the absence of any conflict of interest.

\section{Acknowledgements}

The research was supported by Project Grants (K131996 to PH, FK131864 to AM, FK124632 to BCN and K120335 to TT) of the National Research Development and Innovation Office, an Economic Development and Innovation Operative Programme Grant (GINOP 2.3.2-15-2016-00048 to PH), a Human Resources Development Operational Programme Grant (EFOP-3.6.2-16-2017-00006 to PH), János Bolyai Research Scholarship of the Hungarian Academy of Sciences (to AP) and ÚNKP-19-4 New National Excellence Program of the Ministry of Human Capacities (to AP).

\section{Appendix A. Supplementary data}

Supplementary data to this article can be found online at https://doi.org/10.1016/j.pan.2020.03.018.

\section{References}

[1] Ford ES, Li C, Zhao G, Pearson WS, Mokdad AH. Hypertriglyceridemia and its pharmacologic treatment among US adults. Arch Intern Med 2009;169(6): $572-8$.

[2] Laufs U, Parhofer KG, Ginsberg HN, Hegele RA. Clinical review on triglycerides. Eur Heart J 2019. https://doi.org/10.1093/eurheartj/ehz778. epub ahead of print.

[3] Yadav D, Lowenfels AB. The epidemiology of pancreatitis and pancreatic cancer. Gastroenterology 2013;144(6):1252-61.

[4] Scherer J, Singh V, Pitchumoni C, Yadav D. Issues in hypertriglyceridemic pancreatitis-an update. J Clin Gastroenterol 2014;48(3):195.

[5] Yadav D, Pitchumoni C. Issues in hyperlipidemic pancreatitis. J Clin Gastroenterol 2003;36(1):54-62.

[6] Berglund L, Brunzell JD, Goldberg AC, Goldberg IJ, Sacks F, Murad MH, et al. Evaluation and treatment of hypertriglyceridemia: an Endocrine Society 
clinical practice guideline. J Clin Endocrinol Metabol 2012;97(9):2969-89.

[7] Párniczky A, Kui B, Szentesi A, Balázs A, Szű́cs Á, Mosztbacher D, et al. Prospective, multicentre, nationwide clinical data from 600 cases of acute pancreatitis. PLoS One 2016;11(10):e0165309.

[8] Zhu Y, Pan X, Zeng H, He W, Xia L, Liu P, et al. A study on the etiology, severity, and mortality of 3260 patients with acute pancreatitis according to the revised Atlanta classification in Jiangxi, China over an 8-year period. Pancreas 2017;46(4):504-9.

[9] Roberts S, Akbari A, Thorne K, Atkinson M, Evans P. The incidence of acute pancreatitis: impact of social deprivation, alcohol consumption, seasonal and demographic factors. Aliment Pharmacol Therapeut 2013;38(5):539-48.

[10] Zhang R, Deng L, Jin T, Zhu P, Shi N, Jiang K, et al. Hypertriglyceridaemiaassociated acute pancreatitis: diagnosis and impact on severity. HPB 2019;21(9):1240-9.

[11] Khatua B, El-Kurdi B, Singh VP. Obesity and pancreatitis. Curr Opin Gastroenterol 2017;33(5):374-82.

[12] Zheng Y, Zhou Z, Li H, Li J, Li A, Ma B, et al. A multicenter study on etiology of acute pancreatitis in Beijing during 5 years. Pancreas 2015;44(3):409-14.

[13] Kiss L, Für G, Mátrai P, Hegyi P, Ivány E, Cazacu IM, et al. The effect of serum triglyceride concentration on the outcome of acute pancreatitis: systematic review and meta-analysis. Sci Rep 2018;8(1):14096.

[14] Czakó L, Szabolcs A, Vajda Á, Csáti S, Venglovecz V, Rakonczay Jr Z, et al. Hyperlipidemia induced by a cholesterol-rich diet aggravates necrotizing pancreatitis in rats. Eur J Pharmacol 2007;572(1):74-81.

[15] Wang Q, Wang G, Qiu Z, He X, Liu C. Elevated serum triglycerides in the prognostic assessment of acute pancreatitis. J Clin Gastroenterol 2017;51(7): 586-93.

[16] Yang N, Li B, Pan Y, Tu J, Liu G, Lu G, et al. Hypertriglyceridaemia delays pancreatic regeneration after acute pancreatitis in mice and patients. Gut 2019;68(2):378-80.

[17] IAP WG, Guidelines AAP. IAP/APA evidence-based guidelines for the management of acute pancreatitis. Pancreatology 2013;13(4):e1-15.

[18] Hritz I, Czakó L, Dubravcsik Z, Farkas G, Kelemen D, Lásztity N, et al. Acute pancreatitis. Evidence based management guidelines of the Hungarian Pancreatic Study Group. Orv Hetil 2015;156(7):244-61.

[19] Yokoe M, Takada T, Mayumi T, Yoshida M, Isaji S, Wada K, et al. Japanese guidelines for the management of acute pancreatitis: Japanese Guidelines 2015. J Hepato-Biliary-Pancreatic Sci 2015;22(6):405-32.

[20] Banks PA, Bollen TL, Dervenis C, Gooszen HG, Johnson CD, Sarr MG, et al. Classification of acute pancreatitis-2012: revision of the Atlanta classification and definitions by international consensus. Gut 2013;62(1):102-11.

[21] Charlson ME, Pompei P, Ales KL, MacKenzie CR. A new method of classifying prognostic comorbidity in longitudinal studies: development and validation. J Chron Dis 1987:40(5):373-83.

[22] Wilsnack RW, Wilsnack SC, Kristjanson AF, Vogeltanz-Holm ND, Gmel G. Gender and alcohol consumption: patterns from the multinational GENACIS project. Addiction 2009;104(9):1487-500.

[23] Van Geenen EJ, Van der Peet DL, Bhagirath P, Mulder CJ, Bruno MJ. Etiology and diagnosis of acute biliary pancreatitis. Nat Rev Gastroenterol Hepatol 2010;7(9):495

[24] Yourno J, Henry JB. Rapid amylase and lipase determinations by nephelometry. Am J Clin Pathol 1978;70(1):56-63.

[25] Fallat RW, Vester JW, Glueck CJ. Suppression of amylase activity by hypertriglyceridemia. Jama 1973;225(11):1331-4

[26] Singh A, Shrestha M, Anand C. Acute pancreatitis with normal amylase and lipase-an ED dilemma. Am J Emerg Med 2016;34(5):940. e5-. e7.

27] Sotello D, Rivas AM, Nugent KM, editors. Newly diagnosed acromegaly presenting with hypertriglyceridemic pancreatitis with normal amylase and lipase levels. Baylor University Medical Center Proceedings. Taylor \& Francis 2014.

[28] Baranyai T, Terzin V, Vajda Á, Wittmann T, Czakó L. Hypertriglyceridemia causes more severe course of acute pancreatitis. Clin Lipidol 2012;7(6):731-6.

[29] Wang S-H, Chou Y-C, Shangkuan W-C, Wei K-Y, Pan Y-H, Lin H-C. Relationship between plasma triglyceride level and severity of hypertriglyceridemic pancreatitis. PloS One 2016;11(10):e0163984.

[30] Nawaz H, Koutroumpakis E, Easler J, Slivka A, Whitcomb DC, Singh VP, et al Elevated serum triglycerides are independently associated with persistent organ failure in acute pancreatitis. Am J Gastroenterol 2015;110(10):1497.

[31] Szentesi A, Párniczky A, Vincze A, Bajor J, Gódi S, Sarlos P, et al. Multiple hits in acute pancreatitis: components of metabolic syndrome synergize each other's deteriorating effects. Front Physiol 2019;10:1202.

[32] Tai W-P, Lin X-C, Liu H, Wang C-H, Wu J, Zhang N-W, et al. A retrospective research of the characteristic of hypertriglyceridemic pancreatitis in Beijing, China. Gastroenterol Res Pract 2016;2016.

33] Navarro S, Cubiella J, Feu F, Zambon D, Fernandez-Cruz L, Ros E. Hypertriglyceridemic acute pancreatitis. Is its clinical course different from lithiasic acute pancreatitis? Med Clínica 2004;123(15):567-70.

[34] Goyal H, Smith B, Bayer C, Rutherford C, Shelnut D. Differences in severity and outcomes between hypertriglyceridemia and alcohol-induced pancreatitis. N Am J Med Sci 2016;8(2):82.

[35] Yang F, Wang Y, Sternfeld L, Rodriguez J, Ross C, Hayden M, et al. The role of free fatty acids, pancreatic lipase and $\mathrm{Ca} 2+$ signalling in injury of isolated acinar cells and pancreatitis model in lipoprotein lipase-deficient mice. Acta Physiol 2009;195(1):13-28.

36] Navina S, Acharya C, DeLany JP, Orlichenko LS, Baty CJ, Shiva SS, et al. Lipotoxicity causes multisystem organ failure and exacerbates acute pancreatitis in obesity. Sci Transl Med 2011;3(107). 107ra10-ra10.

[37] Maléth J, Hegyi P. Ca2+ toxicity and mitochondrial damage in acute pancreatitis: translational overview. Phil Trans Biol Sci 2016;371(1700):20150425.

[38] Hegyi P, Petersen $\mathrm{OH}$. The exocrine pancreas: the acinar-ductal tango in physiology and pathophysiology. In: Reviews of physiology, biochemistry and pharmacology, vol. 165. Springer; 2013. p. 1-30.

[39] Kimura W, Mössner J. Role of hypertriglyceridemia in the pathogenesis of experimental acute pancreatitis in rats. Int J Gastrointest Canc 1996;20(3): 177-84.

[40] Pothoulakis I, Paragomi P, Archibugi L, Tuft M, Talukdar R, Kochhar R, et al. Clinical features of hypertriglyceridemia-induced acute pancreatitis in an international, multicenter, prospective cohort (APPRENTICE consortium). Pancreatology 2020;20(3):325-30.

[41] Balachandra S, Virlos I, King N, Siriwardana H, France M, Siriwardena A Hyperlipidaemia and outcome in acute pancreatitis. Int J Clin Pract 2006;60(2):156-9.

[42] Deng L-H, Xue P, Xia Q Yang X-N, Wan M-H. Effect of admission hypertriglyceridemia on the episodes of severe acute pancreatitis. World J Gastroenterol: WJG 2008;14(28):4558.

[43] Zádori N, Gede N, Antal J, Szentesi A, Alizadeh H, Vincze A, et al. EarLy elimination of fatty acids iN hypertriglyceridemia-induced acuTe pancreatitis (ELEFANT trial): protocol of an open-label, multicenter, adaptive randomized clinical trial. Pancreatology 2019;20(3):369-76. 